\title{
The Solid Core (Trephine) Bone Marrow Biopsy Needle; Advantages of Employing A Biopsy Needle with Core Retention Design
}

\author{
Anwarul Islam* \\ Department of Medicine, Division of Hematology/Oncology, Clinical Associate Professor of Medicine, Buffalo General Hospital, Buffalo, \\ New York, USA \\ *Corresponding author: Anwarul Islam, Department of Medicine, Division of Hematology/Oncology, Clinical Associate Professor \\ of Medicine, Buffalo General Hospital, Buffalo, New York, USA
}

\begin{tabular}{lll}
\hline ARTICLE INFO & & ABSTRACT \\
\cline { 1 - 1 } $\begin{array}{ll}\text { Received: } \\
\text { Published: June 04, } 2019\end{array}$ & & $\begin{array}{l}\text { Citation: Anwarul Islam. The Solid Core (Trephine) Bone Marrow Biopsy Needle; Ad- } \\
\text { vantages of Employing A Biopsy Needle with Core Retention Design. Biomed J Sci \& Tech } \\
\text { Res 18(4)-2019. BJSTR. MS.ID.003192. }\end{array}$ \\
\hline
\end{tabular}

\section{Introduction}

The technique of bone marrow trephine (solid core) biopsy was first introduced by Ghedini of Genoa in 1908 when he performed a surgical bone marrow biopsy on a patient to aid in the diagnosis of a hematologic disease. He obtained a sample of bone and marrow from the upper end of the tibia of an adult using a manual trephine [1]. The value of bone marrow trephine biopsy in the investigation and diagnosis of bone and bone marrow disorders has long been recognized [2-4] and has gained acceptance among hematologists and oncologists. This is specifically due to two reasons; (a) the development of new needles $[5,6]$ ensuring that the biopsies can be carried out with minimal discomfort for the patient while imposing little or no damage to the biopsied tissue, and (B) improvements in the technique of processing bone marrow biopsies in plastic (methyl and glycol-methacrylate) which require no decalcification [7]. This approach provides thin (1-2 $\mu \mathrm{m})$ sections of high histological quality that are stainable with Romanowsky type stains (Giemsa or May-Grunwald \& Giemsa) providing excellent cytomorphologic detail of the haemopoietic tissue (Figures $1 \& 2$ ). It has also become apparent that in some cases additional diagnostic and prognostic information can be obtained from an adequately processed and properly stained bone marrow biopsy sections than from a dry film smears alone [8,9]. In general, both procedures are considered essential and complimentary [8]. An optimal clinical evaluation of the bone marrow requires an examination of air dried and well stained smears of the aspirated tissue along with a histopathological evaluation of adequately processed and properly stained core biopsy specimens. Currently several bone marrow biopsy needles are available. Unfortunately, not all of them provide good quality biopsy specimens for histological evaluation or are user friendly.

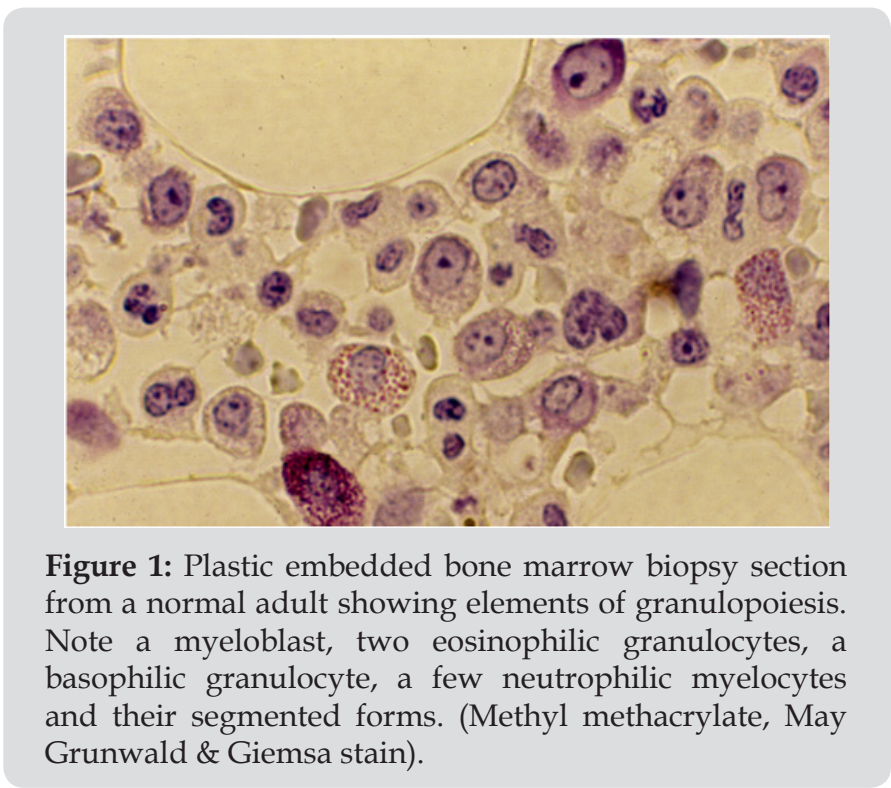




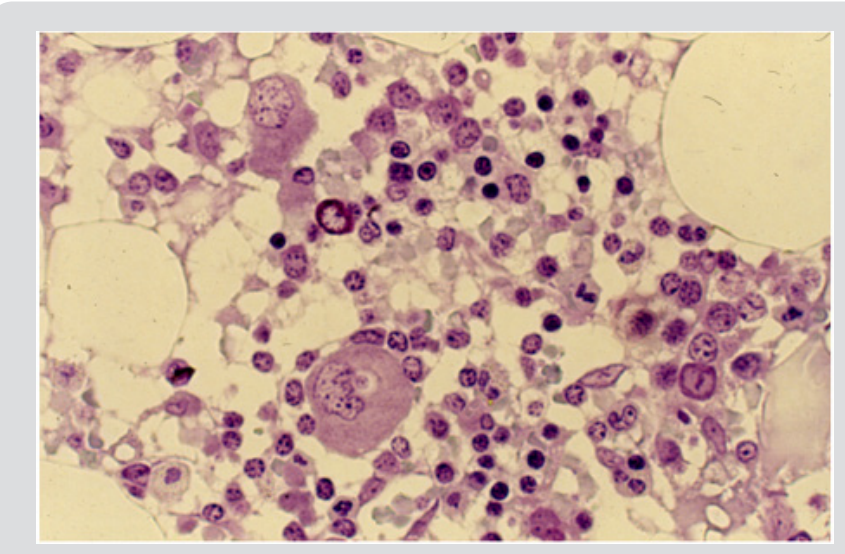

Figure 2: Plastic embedded bone marrow biopsy section from a normal adult showing elements of erythropoiesis in different stages of maturation. Two megakaryocytes and a mast cell can also be seen. (Methyl methacrylate, May Grunwald \& Giemsa stain).

The earlier trephine instruments such as Bordier's [10], Nottar Labhard's [11], Burkhardt's [7] and Gidlund's instruments [12] were large and bulky, contained multiple components, were cumbersome to use, and required an open surgical procedure. Above all they could not be repeated at the same site for at least 4-6 months. In the 1970 s the Jamshidi bone marrow biopsy needle $[13,14]$ presented a significant improvement in the technique of bone marrow biopsy procedure. This needle appeared to offer the best compromise between the larger Bordier's, Notter-Labhardt's, Burkhardt's and Gidlund's instruments and the other less satisfactory Sacker Nordin bone marrow biopsy needle [15]. However, a major drawback of the Jamshidi needle was that the biopsy specimens frequently slipped out of the needle during its withdrawal due to lack of a core retention device (Figure 3) and remained within the patient. This required a second or third attempt and further discomfort for the patient. Furthermore, the Jamshidi needle technique also required rocking or sculling movement or a change in the direction of the tip of the needle to secure the biopsy specimen. As a result, the needles were often bent and damaged.

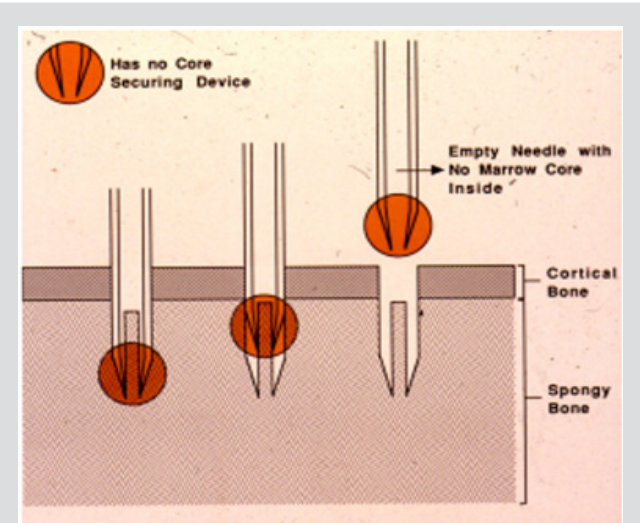

Jamshidi

Figure 3: Schematic representation of a bone marrow biopsy procedure using a Jamshidi needle. It demonstrates that as the needle is withdrawn, the biopsy specimen can slip out of the needle and remain inside the patient.

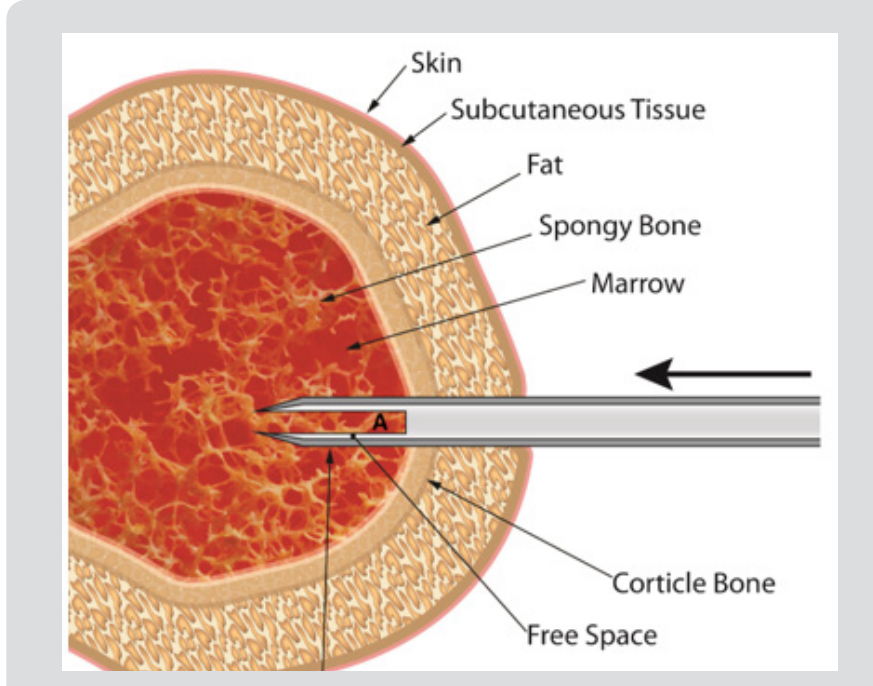

Figure 4: An illustration of a biopsy procedure using a Jamshidi needle. It does not have a core retention device. The needle has been introduced through the skin, soft tissue and cortical bone and into the marrow cavity. It shows the biopsy specimen (A) sitting within the lumen of the biopsy needle.

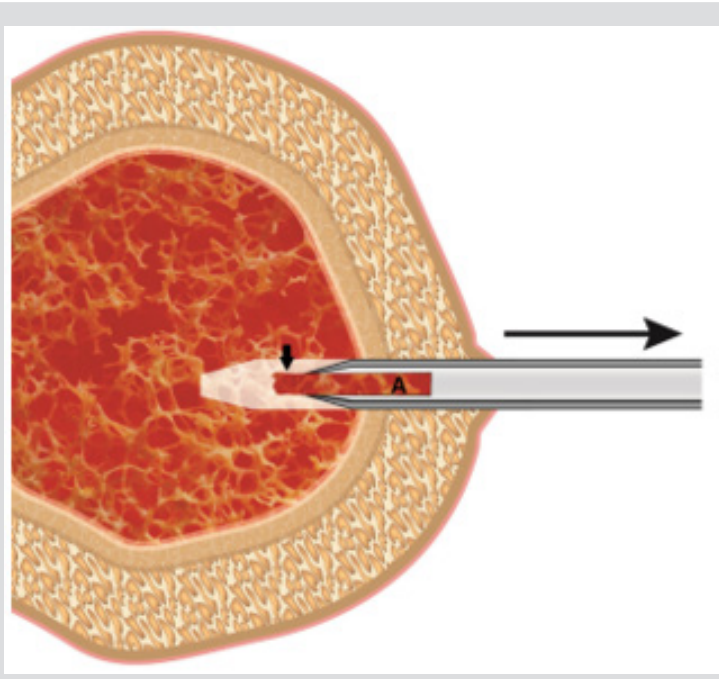

Figure 5: An illustration showing the biopsy needle [containing the biopsy specimen (A)] as it is being withdrawn from the patient's body. It demonstrates that due to the lack of a core retention capacity the biopsy specimen has started to slip out of the needle (short thick arrow).

One of the most important drawbacks of Jamshidi trephine biopsy needles without any core retention device is the fact that as the biopsy needle is being withdrawn from the patient's body, the biopsy specimen contained within the lumen of the needle sometimes start to slip out of the needle (as illustrated in Figures 4-6). As a result, a good portion of the biopsy specimen is caught and remains trapped in the soft tissue and skin. In such circumnstaces it is impossible to extract all of the buried tissue. Furthermore, if and when this happens (see Figure 7) it can bode danger to the patient as there may be a chance of disseminating the disease outside the bone marow cavity. The problem of core loss was soon 
recognized and was overcome by a newly developed bone marrow biopsy needle with a core retention device $[16,17]$. Following the introduction of this latter bone marrow biopsy retentive needle other manufacturers of bone marrow biopsy needles, including the Jamshidi needle recognized that this problem existed and soon developed their own version of needles to capture the biopsy specimen. Each of these needles features different methods of securing a core sample during withdrawal of the needle from the patient. Unfortunately, in the process of doing this, all of these needles significantly complicate the procedure by introducing multiple steps and an assortment of extra parts and components. Indeed, in some cases, these needles contain up to six or more additional accessories (Figure 8).

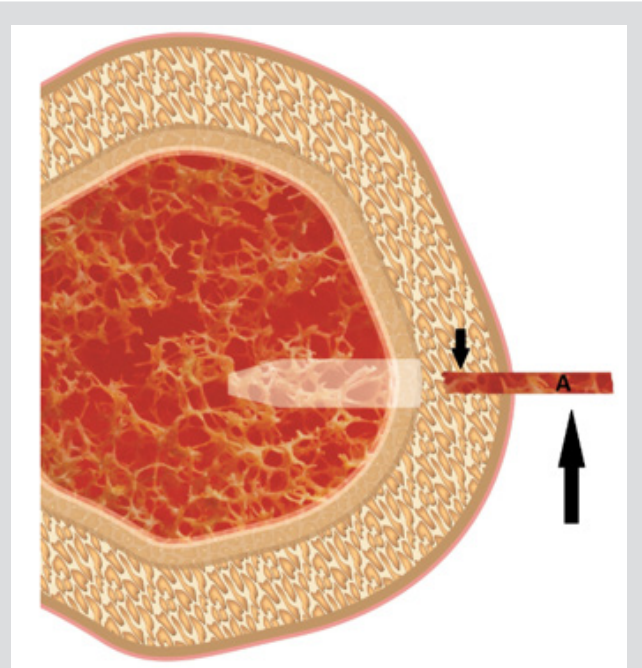

Figure 6: An illustration showing a portion of the biopsy specimen that is trapped in the skin and subcutaneous tissue (short arrow) and a portion of the biopsy that remains on the surface of the skin once the needle has been completely withdrawn (long Arrow).

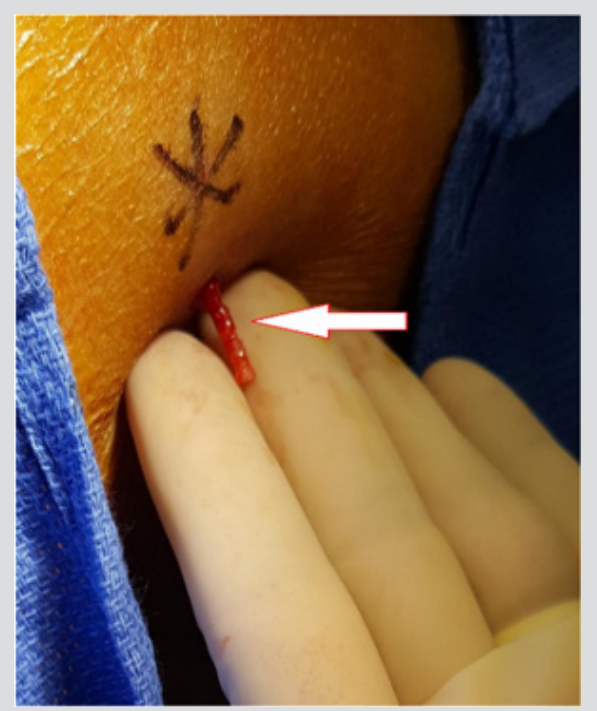

Figure 7: A photograph of a portion of the biopsy specimen that is hanging on the surface of the skin (arrow) once the needle has been completely withdrawn.

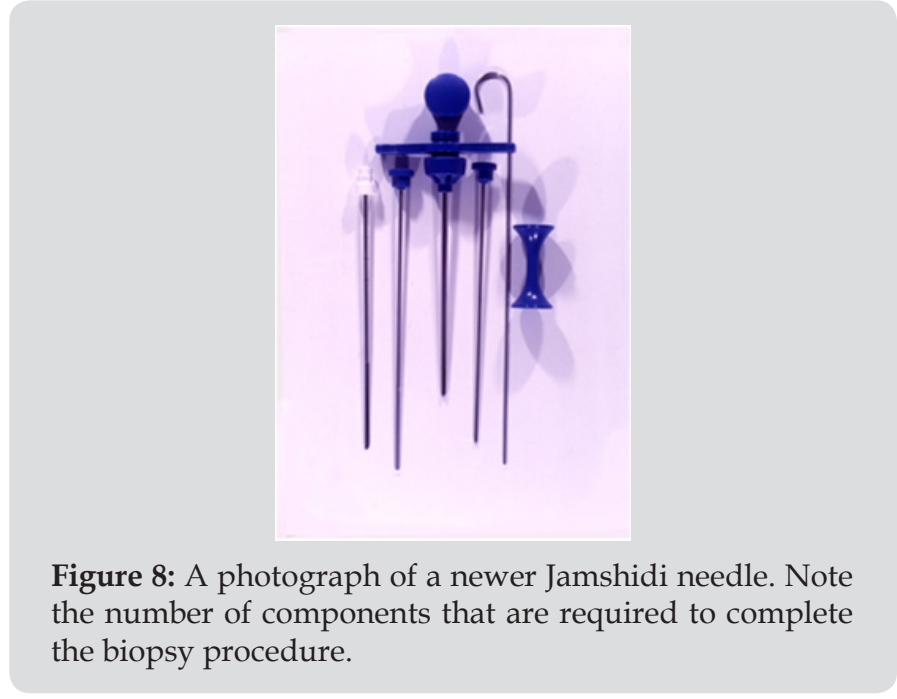

Furthermore, these core capturing devices such as sleeves (Figure 9a \& 9b), coils (Figure 10) or marrow acquisition cradles (Figure 11) can induce considerable crush artifact, particularly at the edges of the biopsy specimen, when they are inserted into the needle and pushed forward over the biopsy specimen in order to grasp and retain it (Figures 12). This technique of capturing the biopsy specimen also reduces the amount of tissue (total width) that is obtained for histological evaluation. A newly developed needle by Islam and Moeller Medical has been designed specifically to protect the sample from loss as well as to deliver histologically intact, undistorted biopsy specimens (Figure 13). One of its advantages is that the intraluminal design offers a free space between the internal wall of the needle and the marrow core and this avoids crushing and compression of the tissue as well as plugging the lumen of the needle. It also helps easy deliver of the core through the proximal end of the needle. Another desired feature is the needle's simplicity and the reduced number of parts and steps required to retrieve the tissue from the needle. In a recent comparative study [18] this needle was found to superior both in respect of the length of the biopsy specimens obtained and its retentive capacity. In addition, the artefactual change and tissue damage was minimal.

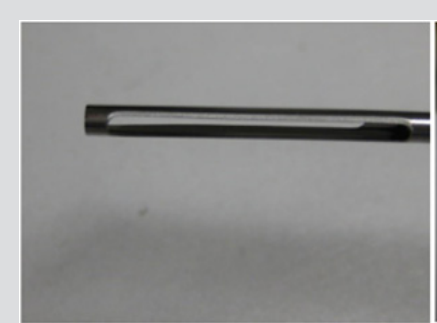

(a)

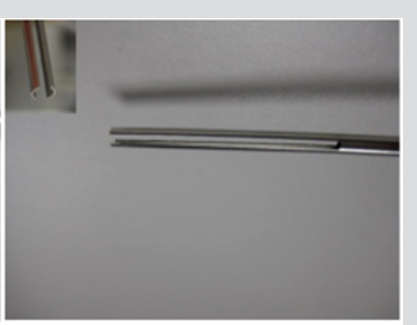

(b)
Figure 9: a) Photograph of the sleeve/spoon that is used to capture the biopsy specimen for the $\mathrm{J}$ needle (Cardinal Health).

b) Photograph of the double sleeve that is used to capture the biopsy specimen for the Trap Lok bone marrow biopsy needle (MD Tech). The inset shows the distal end of the sleeves in greater detail. 


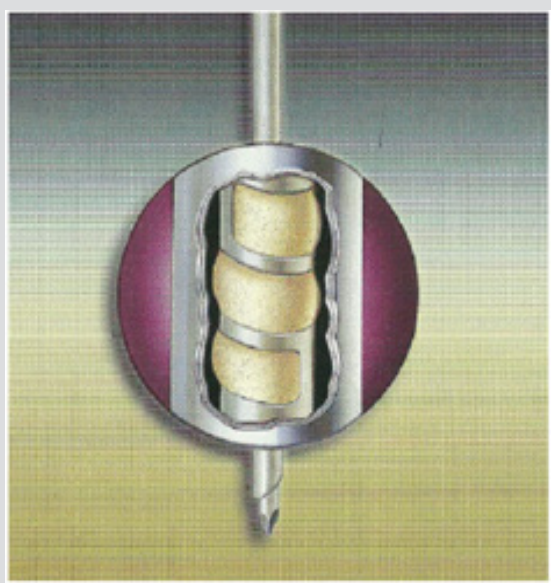

Figure 10: Photograph of the coil that is used to capture the biopsy specimen for the Goldenberg needle (Ranfac).

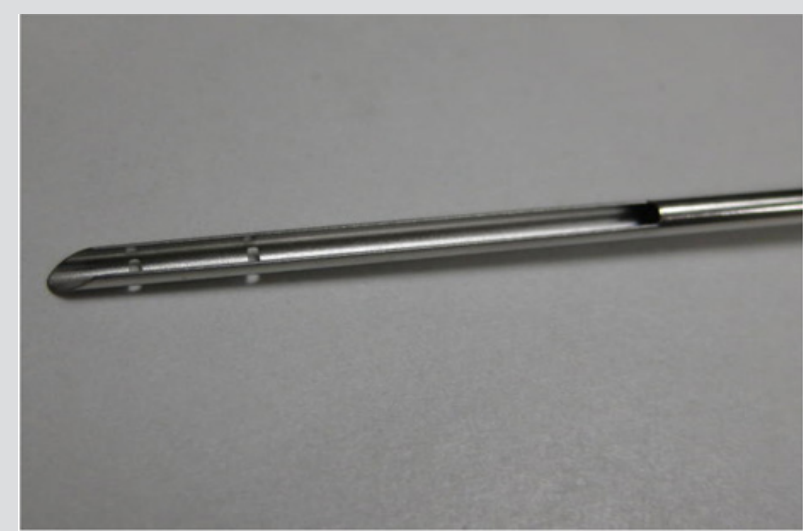

Figure 11: Photograph of the sleeve that is used to capture the biopsy specimen for the Jamshidi (J) needle with marrow acquisition cradle (Care fusion).

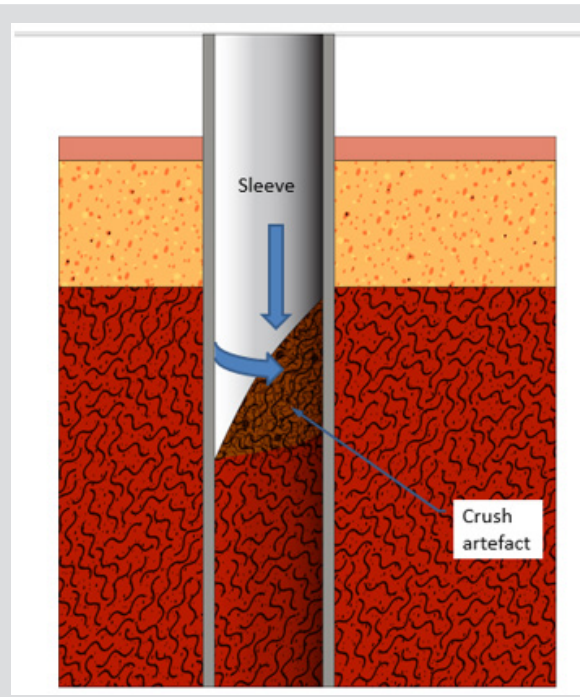

Figure 12: A schematic representation of the capture of the biopsy specimen by the sleeve/marrow acquisition cradle (Cardinal, MD Teck, Care fusion). When the sleeve is rotated and pushed forward over the biopsy specimen it produces considerable crush artifact at the edges of the biopsy specimen thus reducing the total width of the biopsy specimen available for histological evaluation.

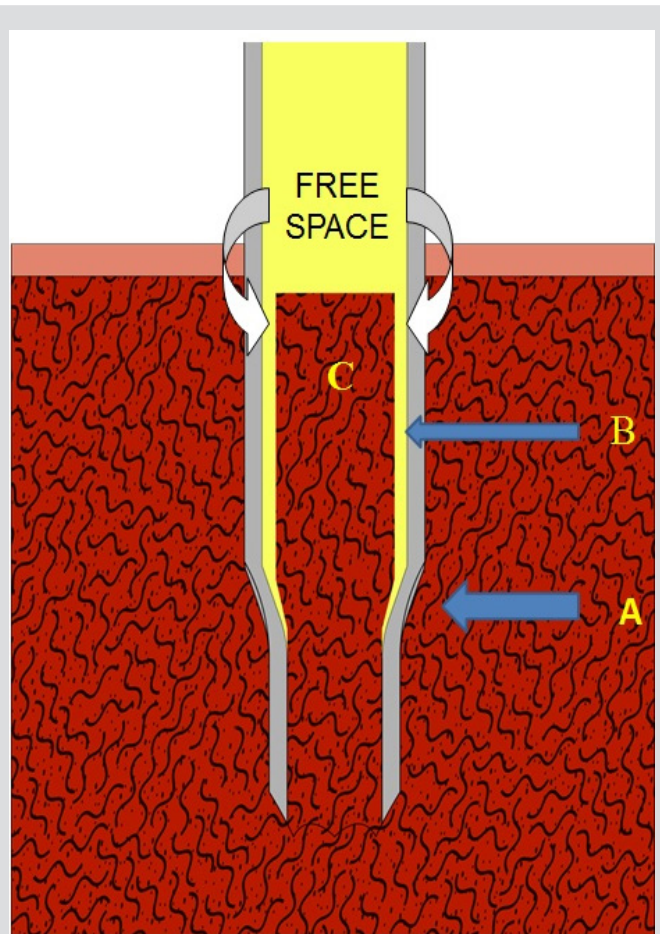

Figure 13: A schematic representation of the biopsy specimen as obtained with the Islam-Moeller biopsy needle. Note the internal step (A) that acts as a shoulder which prevents the biopsy specimen from slipping out of the needle as the needle is being withdrawn from the patient. Note the free space between the internal wall of the needle (B) and the marrow core (C). This free space allows expansion of the tissue, prevents crushing and avoids plugging of the lumen of the needle. It also allows easy delivery of the core through the proximal end of the needle.

\section{References}

1. Ghedini G (1908) Studi sulla patologia del midello osseo umano vivente. I. Punctura explorative tecnica. Clin Med Ital 47: 724-727.

2. Ellman L (1976) Bone marrow biopsy in the evaluation of lymphoma, carcinoma and granulomatous disorders. Am J Med 60(1): 1-7.

3. Burke JS (1978) The value of the bone marrow biopsy in the diagnosis of hairy cell leukaemia. Am J Clin Pathol 70(6): 876-884.

4. Brunning RD, Bloomfield CD, McKenna RW, Peterson L (1975) Bilateral trephine bone marrow biopsies in lymphomaand other neoplastic disease. Ann Int Med 82(3): 365-366.

5. Jamshidi K, Swaim WR (1971) Bone marrow biopsy with unaltered architecture: a new biopsy device. J Lab Clin Med 77(2): 335-342.

6. Islam A (1982) A new bone marrow biopsy needle with core securing device. J Clin Pathol 35(3): 359-366.

7. (1972) Rolf Burkhardt: Bone Marrow and Bone Tissue: Color Atlas of Clinical Histopathology. Springer-Verlag.

8. Pandya A, Patel T, Shah N (2012) Comparative utility of Bone Marrow Aspiration and Bone marrow Biopsy. Journal of Evolution of Medical and Dental Sciences 1: 987-993.

9. Sabharwal BD, Malhorta V, Aruna S (1990) Comparative evaluation of bone marrow aspirate particle smears, imprints and biopsy sections. J Postgraduate Med 36(4): 194-198.

10. Helleberg RI, Sondergaard PH (1975) Bone-marrow biopsy with the bordier trephine. Scand J Haematol 14(2): 123-128. 
11. Notter B, Labhart A (1953) Die Knochenbiopsie, Beschreibung einer einfachen Technik. Schweiz Med Wochenschr 83: 1263-1265.

12. Landys K, Stenram U (1975) Bone marrow biopsy of the posterior iliac crest with Gidlund's instrument in malignant diseases. Scand J Haematol 15(2): 104-108.

13. Jamshidi K, Swaim WR (1971) Bone marrow biopsy with unaltered architecture: a new biopsy device. J Lab Clin Med 77(2): 335-342.

14. Jamshidi K, Windschitl HE, Swaim WR (1971) A new biopsy needle for bone marrow. Scand J Haematol 8(1): 69-72.

ISSN: 2574-1241

DOI: 10.26717/BJSTR.2019.18.003192

Anwarul Islam. Biomed J Sci \& Tech Res

(C) This work is licensed under Creative

Submission Link: https://biomedres.us/submit-manuscript.php
15. Sacker LS, Nordin (1954) A simple bone marrow biopsy. Lancet I: 347.

16. Islam A (1982) A new bone marrow biopsy needle with core securing device. J Clin Pathol 35(3): 359-366.

17. Islam A (2005) A new single use bone marrow biopsy needle. Journal of Biomedical Instrumentation and Technology 39(5): 391-396.

18. Islam A (2017) Bone Marrow Solid Core Biopsy Needle: A Critical Assessment of the Utility, Benefits and Limitations of the Instruments Employed in Current Day Hematology and Oncology. J Clin Pathol 71(6): 475-482.

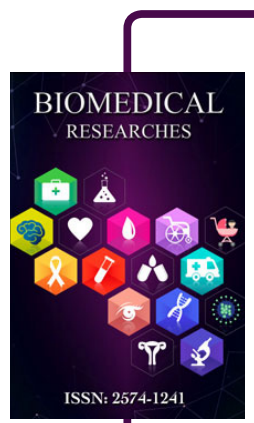

\section{Assets of Publishing with us}

- Global archiving of articles

- Immediate, unrestricted online access

- Rigorous Peer Review Process

- Authors Retain Copyrights

- Unique DOI for all articles

https://biomedres.us/ 